\title{
IMP2.0 Migration Collaborative Platform and e-Services
}

\author{
Nineta Polemi, George Pentafronimos, and Theodoros Ntouskas \\ University of Piraeus, Dept. of Informatics, Karaoli \& Dimitriou 80, \\ 18534, Pireaus, Greece \\ \{dpolemi, gpentas, tdouskas\}@unipi.gr
}

\begin{abstract}
Legal immigration is a complex, multi dimensional issue and the European Commission (E.C.) project ImmigrationPolicy2.0 (IMP2.0) [1] considered it as such by studying its legal, societal and policy implications before proposing and implementing holistic e-migration services contributing towards participatory governance and the harmonization of existing policies and practices. This paper outlines the IMP2.0 social, policy and legal research results which led to the design and implementation of targeted e-migration collaborative services by presenting the identified requirements and describing the services provided by the IMP2.0 web platform.
\end{abstract}

Keywords: legal immigration, collaborative technologies, e-migration services.

\section{Introduction}

IMP2.0 [1] is a technological project driven from the needs arising in the migration policy field. Social Integration, Social Cohesion, Security, Privacy and Interoperability are the most important European Union (E.U.) policy objectives that IMP2.0 directly addresses. It adopts a bottom up approach by analyzing all aspects (legal, societal, policy) of the complex migration employment problem (the most important part of a Social Integration Policy) and provides e-services which contribute towards harmonizing the efforts for establishing a common E.U. migration employment policy.

It provides an innovative IT instrument to both migration related communities (policy makers and legal immigrants), using new technologies and opens new research areas (visualization, collaborative modeling and graphics, governmental process management systems, collaborative decision making). In contrast to the present situation of IT governmental tools, IMP2.0 paves the way for a new research area in "Innovative migration electronic systems".

In this paper we outline the IMP2.0 social, policy and legal research results which led to the design and implementation of targeted e-migration collaborative services and it is organized as follows: In Section 2, the E.U. policy and legislation harmonization efforts related to employment migration are outlined and open problems and gaps at practical level are identified. In Section 3, the user requirements as reported in the IMP2.0 survey involving four hundred and sixty eight (468) stakeholders (policy makers and legal immigrants) in the migration employment 
community are presented. Considering these requirements, IMP2.0 designed and implemented targeted e-migration services, in order to contribute effectively towards the efforts in harmonizing E.U. migration employment policies as described in Section 4. The paper concludes with Section 5 in which the main results of the paper are outlined and further research propositions are provided.

\section{Migration Employment Policies and Legislation}

\subsection{European Union Efforts}

IMP2.0 performed a detailed desk study on migration policies at national and European level. In this section the main results of the European level desk study will be presented (for detailed analysis the reader is referred to [3]).

The European Union (EU) Council acknowledges that migration employment issue, by its very nature, can be better addressed at European rather than at national level. It emphasizes the importance in harmonizing migration policies [10] starting its efforts towards this direction from 1999 with its three main policy Programmes, Tampere, Hague and Stockholm, [4]: The Tampere program (1999-2004) in which the E.U. leaders at the 1999 E.U. Council in Tampere (Finland) agreed upon that a comprehensive approach to migration addressing political, human rights and development issues in countries and regions of origin and transit is needed. This requires improving living conditions and job opportunities, preventing conflicts and consolidating democratic states and ensuring respect for human rights, in particular rights of minorities (women and children). Partnership with third countries concerned is also a key element for the success of such a policy, with a view to promoting cooperative development. From a legislative point of view, the main achievements during the period of implementation of the Tampere program have been the following:

- Family reunification - The Council Directive 2003/86/EC [14] on the right to family reunification. Member States' legislation had to comply with this Directive not later than 3 October 2005.

- E.U. long-term resident status - The Council Directive 2003/109/EC [13] on a long-term resident status for third country nationals who have legally resided for five years in the territory of a Member State. Member States legislation had to comply with this Directive by 23 January 2006.

- Students - A Directive on the conditions of admission of third-country nationals for the purposes of studies, pupil exchange, unremunerated training or voluntary service was adopted by the Council Directive 2004/114. Member States' legislation must comply with the Directive by 12 January 2007.

- Researchers - A Directive for the facilitation of the admission of researchers into the E.U. was adopted by the Council Directive 2005/71.

The Hague program (2005-2010) sets the objectives for strengthening freedom, security and justice in the E.U. for this period. The 2005 E.U. Council, taking into account the outcome of discussions on the Green Paper on an E.U. approach to 
managing economic migration (COM (2004) 811) addressing labor migration, best practices in Member States and its relevance for implementation of the Lisbon strategy, invited the Commission to present a Policy Plan on Legal Migration (COM (2005) 669). The document foreshadowed the proposal for a directive on a single application procedure for a single permit for nationals of third countries to reside and work lawfully in the territory of a Member State and on a common set of rights for third-country workers legally residing in a Member State, which was adopted by the Commission in October 2007 (COM (2007) 637 final). In September 2005, the Commission adopted the communication 'A Common Agenda for Integration Framework for the Integration of Third-Country Nationals in the European Union' (COM (2005) 389).This Communication provides new suggestions for harmonization action both at E.U. and national level. In December 2005, the E.U. Council adopted the Global Approach to Migration, and considers migration issues as integral part of the E.U.'s external relations.

In June 2006 the Commission presented the Second Annual Report on Migration and Integration [SEC (2006) 892] which provides an overview of migration trends in the E.U. In May 2007, the second edition of the 'Handbook on Integration for policymakers and practitioners' was issued focusing on mainstreaming immigrant integration, housing in an urban environment, economic integration and integration governance. In September 2007, the Third Annual Report on Migration and Integration (COM (2007) 512) depicts the continued monitoring process of harmonized policy developments on admission and integration of third-country nationals in the EU. The 2008 E.U. Council endorsed the Global approach to migration. Its purpose is, to create a coherent policy approach in the area of migration: Development policy, measures to encourage legal migration and fight illegal immigration, as well as managing demand for skilled labor in a framework of dialogue, cooperation and partnership with countries of origin and transit.

In 2009, the Commission adopted a directive on the admission of highly-skilled third country nationals, the so-called EU-Blue Card, a fast-track procedure for issuing a special residence and work permit under more attractive conditions. It is the only directive derived from the Policy Plan on Legal Migration from 2005 adopted to date.

The Stockholm Program (2010-2014) approach differs from its predecessors (Tampere Program and Hague Program) with regard to several aspects. For example, the Hague Program emphasized harmonizing migration and asylum policies across Member States, where the Stockholm Program prioritizes initiatives promoting cooperation between the Member States to find practical solutions [11]. It also seeks to use soft law such as guidelines and stand-alone E.U. agencies, rather than the hard law envisioned in the Maastricht Treaty.

The program sets out the following priorities in the area of immigration, in which the relevance of labor migration is curtailed compared to the Hague Program:

- Global Approach to Migration: The need to identify common interests with third countries is highlighted.

- Migration and Development: Facilitating remittances, cooperation with diaspora groups, and promoting circular migration constitute EU's priorities in the migration development nexus. 
- Labor Migration: The need for improved information and data on skills needs, skills recognition and development as well as skills matching with third countries were highly considered for further actions.

- Rights for third-country nationals: Third-country nationals shall be endowed with "rights and obligations comparable to those of E.U. citizens" by the end of the program's period.

- Integration: Within the program several ideas in the area integration are proposed, e.g. the development of common European modules, as well as E.U.-wide indicators to monitor the results of harmonized integration policies.

- Illegal Migration: The need for a sustainable return policy supplemented by encouragement of voluntary return, and renewed efforts to sign readmission agreements with more countries of origin and transit.

- Unaccompanied Minors: Unaccompanied minors, not addressed in the previous programs, are included in the Stockholm Program.

In April 2010 the Commission adopted an action plan on the Stockholm Program (COM (2010) 171 final) to implement the political priorities set out in the program.

The third edition of the Handbook on Integration for policy-makers and practitioners was published in April 2010 and the Commission presented an agenda for new skills and jobs entitled "A European contribution towards full employment" (COM (2010) 682 final). In 2011 a New Agenda for Integration of third country nationals will be launched, to provide improved structures and tools to facilitate the exchange of knowledge, collaboration and the mainstreaming of integration priorities of the Member States.

\subsection{Harmonization in Practice - The IMP2.0 Experience}

Despite the above mentioned collaboration efforts at European level, the adopted national employment migration policies are still divergent and they do not comply with the E.U. Council directives. As a result the processes and documents followed to implement common E.U. migration employment procedures (e.g. issuing of work permits) at national level are neither cross-recognized nor cross-accepted [12].

During the IMP2.0 project the five E.U. countries involved (Germany, Italy, Spain, Greece and Estonia) found that the processes followed to carry out their three common employment migration procedures (Issuing residence permits; Recognition of qualification achieved in non-E.U. countries; Estimating the number of residence permits that will be issued annually) were all sustainably different [3]. These procedures were based on particular national laws that they were not harmonized with the E.U. directives.

For example, regarding the first common migration employment procedure, Issuing residence permits for dependent employment; the five IMP2.0 involved countries exert different processes for granting legal access to the labor market for third-country nationals. With respect to documents type (e.g. individual work permit, residence permit for employment), involved agents and governmental level, legal conditions, order of consecutive process-steps etc. the national processes vary considerably [3] (see e.g. in Figs. 1,2 the different processes followed in Greece and Germany). 

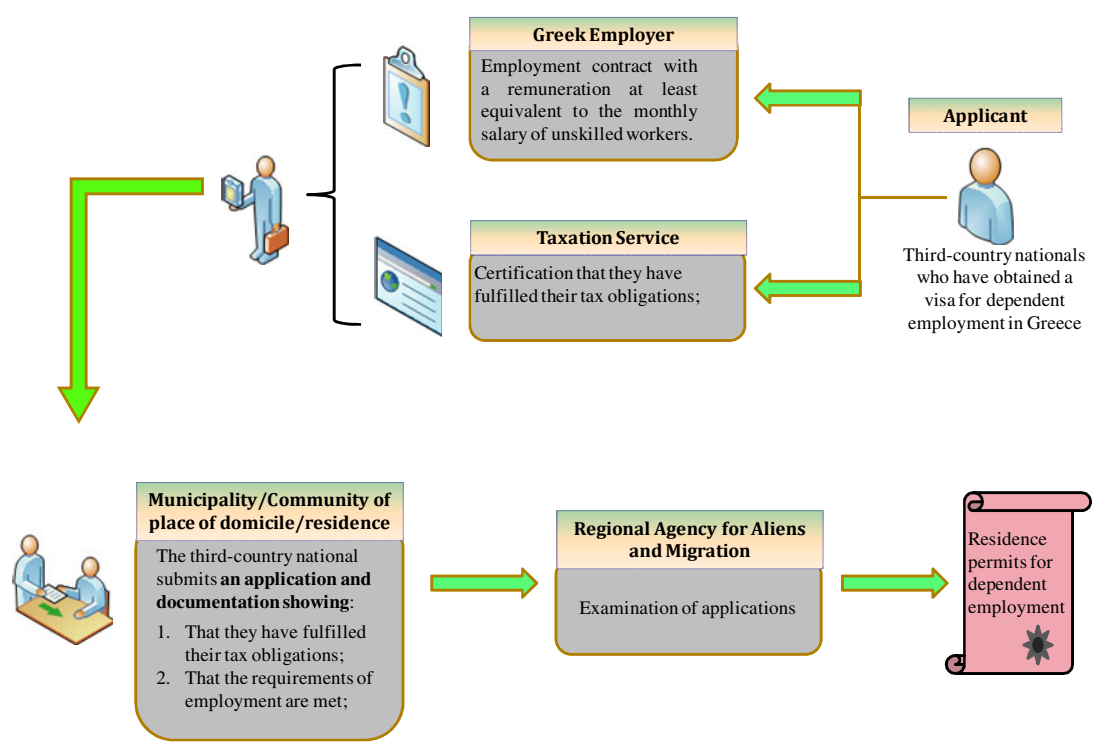

Fig. 1. Greek Procedure [3, p.50]

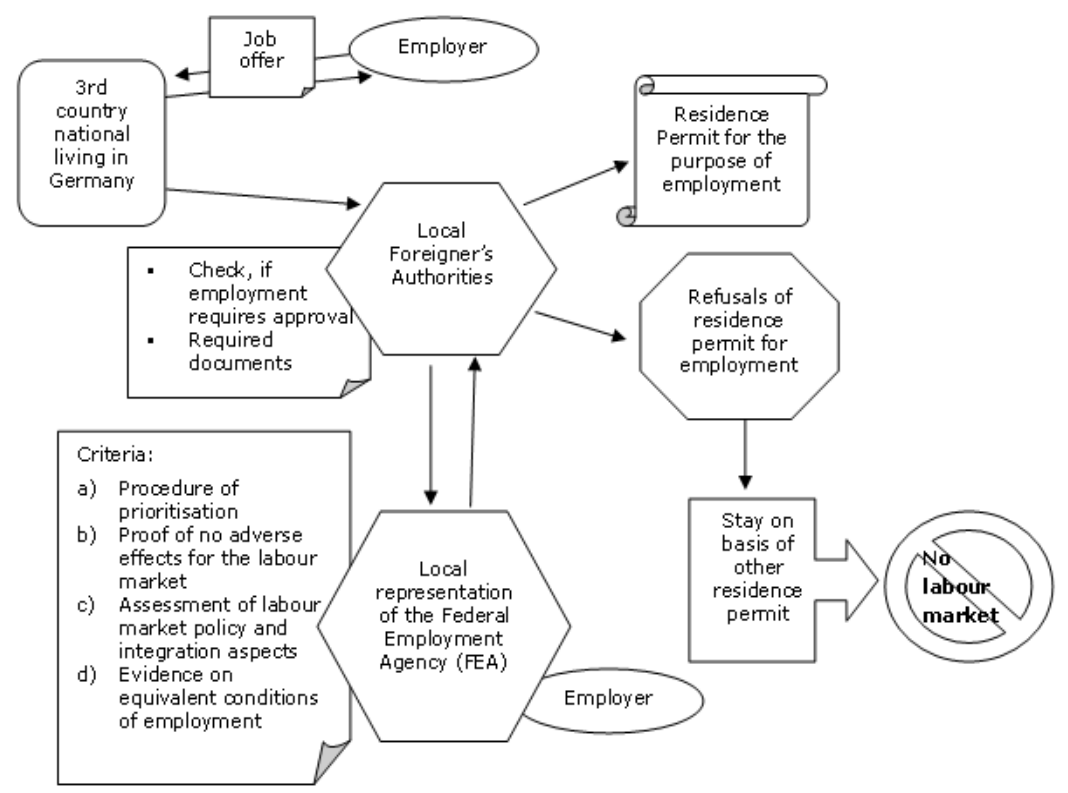

Fig. 2. German Procedure [3, p.76] 
The variation of heterogeneous processes, different types and formats of documents involved result to the non-cross border recognised procedures not allowing the free-movement of legal residents (e.g. legal immigrants, second generation immigrants) in the European continent; damaging the common efforts to control the increasing migration employment wave throughout the European continent, to better balance the European labor marker and to enhance the European competiveness in a holistic way.

IMP2.0 finally concluded that the increased number of decision makers and stakeholders involved in migration policies, increased and diverged legislations and implemented migration procedures, different organizational structures, large and inhomogeneous legacy systems involved, cause a "chaos" in the monitoring of national policies and the harmonization of procedures, processes and data formats. Traditional decision making instruments (e.g. face-to face meetings, workshops and conferences) at political level need to be supported with new innovative governmental IT tools (e.g. for policy modeling, business process management, visualization, collaborative decision making) in order to accelerate the harmonization efforts.

\section{Societal Aspects - The IMP2.0 Requirements' Analysis}

The two migration communities (stakeholders and legal immigrants) need to be involved in the processes of drafting and adopting harmonized realistic policies. IMP2.0 used an explorative multi-methodological approach to realize their requirements and needs consisting of a workshop [5], desk research (results are outlined in the previous section), and questionnaires for both communities in various languages. In this section we will present the European level analysis of the IMP2.0 questionnaires (for the national level analysis and more details the reader is referred to [2]).

IMP2.0 integrated an open-source software tool (based on the PHP framework Symphony 1.0-www.symfony-project.org-) that enables the design, development and deployment of on-line questionnaires. The IMP2.0 questionnaire tool comprises two main modules: One is responsible for the management of online questionnaires while the other undertakes the collection of answers, extraction of results and the generation of statistical data and related reports. The privacy of the responses as well as the effective management of all users' interactions with all the systems, components and software tools, in terms of security, privacy and trust, in the IMP2.0 web platform is undertaken from an advanced, standards-based (e.g. WS-Federation, WS-Trust), centralized and federated Identity and Access Management (IAM) system, which is based on the open source implementation of OpenSSO [9].

Two types of questionnaires [1] were generated in order to capture the requirements of both migration communities and they were translated in the native languages of the above countries and also in Turkish, Albanian and Russian (the mother tongue of the majority of legal immigrants in Germany, Greece and Estonia respectively). 
Altogether four hundred and sixty eight (468) stakeholders and legal immigrants participated in the IMP2.0 questionnaire process from the five participating countries (see Table 1).

Table 1. Sample of the Requirement Analysis [2, p.25]

\begin{tabular}{lccc}
\hline Country & Stakeholders & Immigrants & Total \\
\hline Greece & 22 & 140 & $\mathbf{1 6 2}$ \\
Italy & 14 & 111 & $\mathbf{1 2 5}$ \\
Germany & 17 & 85 & $\mathbf{1 0 2}$ \\
Estonia & 15 & 51 & $\mathbf{6 6}$ \\
Spain & 2 & 11 & $\mathbf{1 3}$ \\
Total & $\mathbf{7 3}$ & $\mathbf{3 9 8}$ & $\mathbf{4 6 8}$ \\
\hline
\end{tabular}

The European level IMP2.0 requirements are summarized in the next subsection (for the extensive IMP2.0 requirements analysis the readers is referred to [2]).

\subsection{Legal Immigrants Requirements}

Information: Migrants need more and better quality information about the practices and procedures in migration/ integration/ employment field. Information has to be clear and simple (less bureaucratic), comparable (between different countries) and presented in more languages. Access to information via electronic channels, especially web, is desired. But it is important to keep in mind that in addition to electronic media, more conventional means for providing information (such as press for example) have to be used in parallel. Most needed information is about employment/ business opportunities, job/ business regulations and migration/ labor market legislation.

Collaboration: Immigrants are interested in participating and collaborating among them and with the policy makers in the policy making process. The goal to include migrants in the policy formulation process could be further promoted by focusing topics of special concern such as registration and recognition of skills and qualification, restrictive regulations of work and residence permit. Migrants are interested to propose their ideas and suggestions to improve the practices and policies in the migration/ integration/ labor field, i.e. to participate in more collaborative policy-making, so possibilities for providing feedback to migration organizations have to be created. Areas for action are for example: registration and recognition of skills and qualification, restrictive regulations of work and residence permit, lack of information and communication, high bureaucracy.

To increase the migrants' participation in policy-making and improvement of procedures, room for debates and discussions should be created, where migrants/ migrant groups/ Non Governmental Organizations (NGOs) could interact with each other as well as with public administrators and policy makers exercise a two-way communication. 
Training: Training in the language and culture of the hosting language and culture is among their main concern. The available training channels are either inadequate or very expensive and time consuming requiring high bureaucracy.

Migrants are not well aware and feel confused about the possibility of processing their migration related documents online. Therefore more information, guiding and trainings need to be offered to popularize these services as well the services need to be simplified. Migrants are most interested in residence and work permit procedures.

\subsection{Stakeholders Requirements}

Migration policies (political level): With respect to economic/labor Migration policies stakeholders revealed a general demand for a comprehensive strategic approach for managing economic immigration. For instance, a lack of knowledge on political programmes to manage labor migration can be assessed as an indicator for the absence of a comprehensive strategic approach: Solely $25 \%$ of the stakeholders know a past, running or planned labor migration Programme in their home country. Also, it was found that stakeholders identify the need for enhancement of labor migration monitoring and means to efficiently match labor demand and supply. With respect to integration policy requirements a general demand for exchange on and further development of integration policies was identified.

Practical work (practical level), Institutional cooperation requirements: Stakeholders in all participating IMP2.0 countries require internet-based structures for cooperation or dialogue with international organizations and EU-institutions, especially on labor migration. The conclusion, inter alia, is based on the finding that almost unanimously, stakeholders in all IMP2.0 participating countries ascribed high importance to international cooperation in the area of labor migration. It was found that the vast majority of stakeholders do not participate in joint projects addressing labor migration.

Stakeholders require cooperation on a wide range of issues. The two most important once seem to be labor migration and exchange of good practices. Further issues of cooperation are: harmonization of policies, practices and procedures, legislation, statistical and analytical data, recognition of qualifications, migration technologies, national procedures, migration projects, illegal employment, labor market and entrepreneurship, residence and work permits, social security issues, education, problems and priorities of political intervention, integration supporting programmes, monitoring of migrant employment, monitoring of migrant selfemployment, targeted training on migration issues, simplification of documents.

Process requirements: Stakeholders require communal and regional networks linking different migration and integration agents for instance, communal and regional promotion and coordination of local policies, participation of citizens, and dissemination of good practices. They also revealed that these processes would need to be enhanced by fostering networks throughout all different governmental levels also including civil society agents.

Administrative procedures requirements: Stakeholders would appreciate an infrastructure for electronically processing of administrative migration related issues 
such as application or renewal of civil status documents related to employment (e.g. work permits, residence permits, family reunification documents).

Information requirements referring to the information provider: A clear claim of stakeholders in three out of five countries included is not to "reinvent the wheel". They rather require an "umbrella portal" for information sources instead of another source presenting single information. As stakeholders said, the umbrella, of course, should not solely apply for information also for other online services, such as service for matching labor demand and supply.

Specific requirements: Political areas for which stakeholders see a need for action are: the development or enhancement of a comprehensive national strategic approach for managing economic immigration; the enhancement of labor migration monitoring; efficiently match labor demand and supply; exchange on and further development of policies addressing the integration of migrants into the economy.

The IMP2.0 requirements' analysis revealed the design of the IMP2.0 new emigration services described in the next section.

\section{The IMP2.0 Collaborative e-Migration Services}

Based on the IMP2.0 user requirements analysis described in the previous section IMP2.0 project defined a number of advanced and highly-sophisticated e-migration services [3] that aim to support both legal immigrants and migration stakeholders in their difficult efforts for effective integration and collaborative policy making and harmonization respectively. The main services to be piloted and offered by the IMP2.0 web platform [6], [7], [8] are depicted in the following figure along with the identified user requirements for each target group:

\section{Users Requirements}

\section{Services}

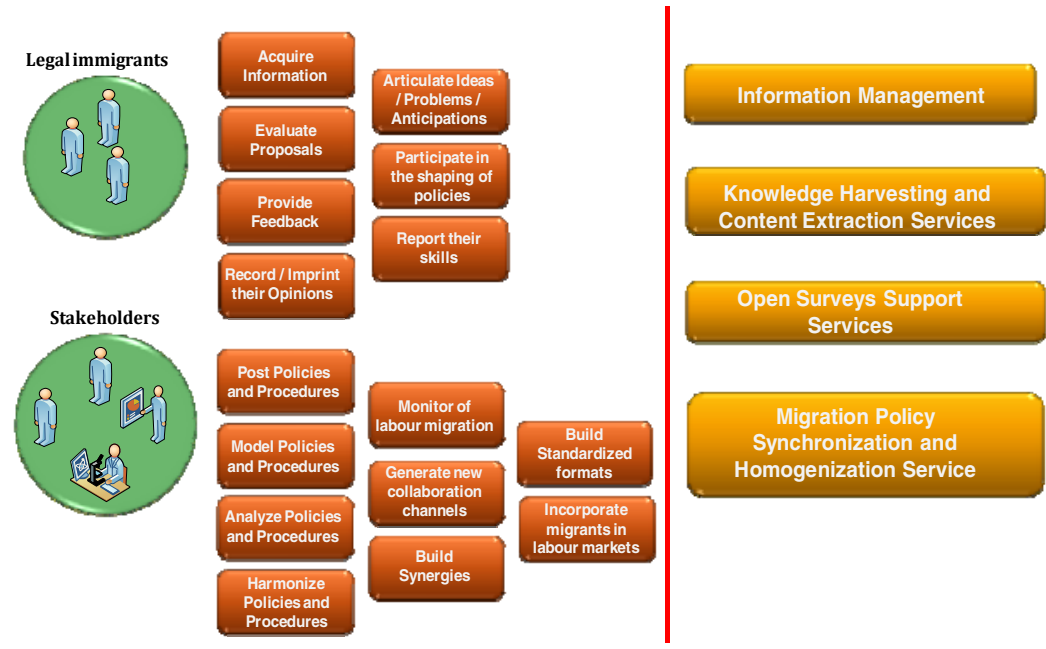

Fig. 3. IMP2.0 User requirements and matching services 
As depicted in the figure above, in order to satisfy the identified requirements IMP2.0 designed and implemented the following e-migration services:

Information Management Services (IMS): IMP2.0 integrated a user-friendly and robust content management system serving as a vehicle for educating end-users with respect to existing policies and regulations, as well as other valuable but distributed information. Specifically, both groups of IMP2.0 end-users (i.e. legal residents, migration stakeholders) will benefit from ubiquitous and user-friendly web interfaces in order to contribute their valuable information sources (i.e. electronic documents, press reports, web links, digitalized migration-related civil status documents, etc.). Also they will be able to search and access these information assets and efficiently classify them based on a properly designed IMP2.0 taxonomy (see [4], Section 2.3.1.1). It will provide seamless access to a sustainable, scalable, structural and searchable inventory, focusing on migration related topics (e.g. National migration policies/legislation/best practices).

This service provides an intuitive and simple interface that enables users to upload their contributions by providing a set of valuable and required (through the use of appropriate control mechanisms) metadata which describe each insertion based on a number of indispensable characteristics. This set of metadata includes the title and description of each information asset, a web-link when applicable as well as a number of indices that characterize the content of each contribution tagged through the integrated tree structure that represents the IMP2.0 taxonomy. The taxonomy has been defined based on the knowledge and experience in migration issues of IMP2.0 partners and has been developed using XML and javascript technologies so as to provide the desired levels of flexibility, extensibility and ease of use when accessed by the end-users for semantically tagging the content they contribute to the IMP2.0 digital library.

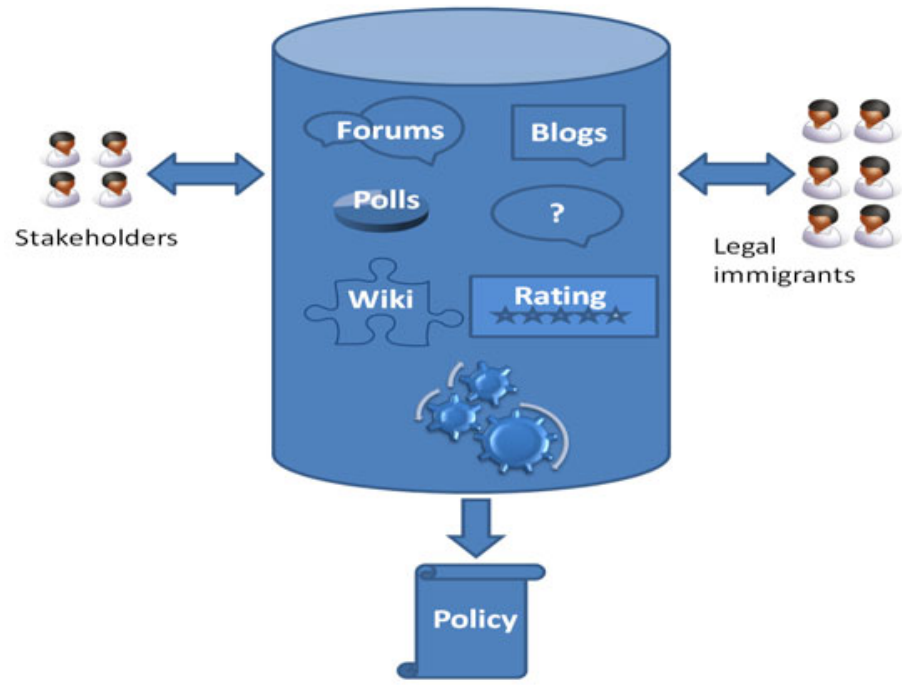

Fig. 4. Knowledge Harvesting and Content Extraction Services 
Knowledge Harvesting and Content Extraction Services (KHCES) (Fig. 4): will integrate advanced data collection technologies and tools as well as interactive frontend user interfaces in order to collect "Open Intelligence" and exploit the "wisdom of the crowds". Specially, it will provide the means for collecting unstructured information and gathering different opinions, views and experiences on migration policies, national practices and procedures regarding civil status documents. This will be achieved by developing a trusted collaborative environment composed by web 2.0 tools like wikis, blogs, etc. or through graphic models thus enabling open participation, direct and multidimensional feedback, Open discussions, as well as the opportunity for gaps identification and proposal of adequate solutions.

Open Surveys Support Services (OSSS): On-line questionnaires, surveys, polls, collaborative documents, and open debates will be used to compose and provide this service to both groups of end-users (i.e. legal residents, migration stakeholders). By accessing and consuming this type of services, IMP2.0 users will be able to exchange diverse proposals, support controversial ideas, positive and negative opinions, answer multiple choice questions and provide both open and structured reasoning as well as their valuable knowledge and experience.

This will be achieved by integrating open-source software tools and specialized Web2.0 components which will enable distributed information acquisition and centralized data management and provide capabilities for statistical analysis and production of reports. The online IMP2.0 questionnaire tool has already been as described in the previous section.

Migration Policy Synchronization and Homogenization Service (MPSHS): This service enables migration policy and decision makers, public administrators, politicians and experts to work and collaborate towards harmonized E.U. migration policies and procedures. Specifically, the objective of this service is to support migration stakeholders in posting and drafting migration policy text, developing and testing policy models, evaluation scenarios ("what-if process") and accessing valuable and efficiently processed statistical data. Migration stakeholders (notably decision and policy makers) will be able to benchmark national practices, policies, procedures and studies as well as to perform assessments in terms of legislation, organizational, political and security characteristics, identify penetration/acceptance rates and effectively forecast, in order to overcome existing obstacles with respect to E.U. directives and best practices.

To achieve these, the ImmigrationPolicy2.0 workplan takes provision for technical implementation activities, which are mainly focused on the integration of readily available $R \& D$ open source and free-license components. The main objectives of the technical implementation and integration tasks of the project are two-fold:

- To establish a highly agile automation environment, that could boost both the reengineering and the integration of migration related processes. This environment will facilitate changes in the migration related processes and services, through enabling the flexible re-composition of complex policy-making and/or harmonization migration services. 
- To compose and deploy the services and processes required to operate the project's pilot services. The composition will leverage the SOA environment and BPM tool of the ImmigrationPolicy2.0 platform.

- To provide a number of tools facilitating citizens participation, government modelling and policy development, as well as support for Open Surveys.

The first step of the integration efforts of the project involves the development of a basic backbone infrastructure for the project pilots. This infrastructure comprises a portal (i.e., consisting of Web2.0 components) enabling end-users participation and interaction, a CMS enabling the management of migration information assets and related portal content, as well as the middleware infrastructure (i.e. application servers, enterprise service bus) that will provide the SOA environment. Notably, this basic infrastructure will hold the data structures of the project including taxonomies, the XML-based and e-Gif enabled content objects, while also providing related tools for the effective collection of data and simple query execution (e.g. online forms, questionnaires etc.) as well. In addition it will provide:

- Advanced content management tools such as rich text editors, live page editing and scheduling, and advanced document managers.

- Web 2.0 aware technologies with their own set of authorizations, message boards for facilitating conversations around migration-based topics, blogs for allowing users to convey information and RSS feeds from the last mentioned message boards and blogs within ImmigrationPolicy2.0.

- A multi-tier search engine so that end-users are able to search relevant information throughout an entire web interactive portal, within specific portlets such as Wikis, Message Boards, other Web 2.0 aware technologies and even in external integrated applications through its advanced multiple interfacing module.

- Intuitive front end user interfaces that will share a set of common characteristics to promote user friendliness and accessibility: they will be multilingual, in order for users to easily toggle between different language settings and they will follow standardized best practices for accessibility (especially for special groups).

- Web publishing tools so to easily create and manage content, from a simple article of text and images to fully functional web sources.

Summarizing, IMP2.0 implements a range of highly sophisticated services in order to provide a robust and sustainable IS/IT collaboration framework that is able to support decision-making in the critical domain of migration. Integrating advanced tools for collecting, analyzing and sharing diverse information and supporting policy-making decisions by providing the opportunity for all key players to work together and contribute their knowledge and experience, the proposed solution delivers an efficient synchronization framework capable to leverage existing traditional practices.

\section{Conclusions}

For more than 20 years now (from the Maastricht Treaty, 1986, to the Treaty of Amsterdam in force since 1999) the Member States have joined forces to combat 
international phenomena such as illegal immigration. There is an urgent, (acknowledged by the ongoing Amsterdam Treaty and the E.U. Councils' programmes) need for more effective, collaborative actions among Member States in order to harmonize national migration policies and specific migration procedures.

The technological, policy-driven, IMP2.0 project contributes directly to these needs and responds to the invitation of the E.U. Council for the development of information systems that will contribute towards a common E.U. migration policy. IMP2.0 performed a social analysis on the migration needs and requirements involving both stakeholders and legal immigrants in order to propose e-migration services considering all aspects (policy, legal, societal). Collaborative technologies are the IMP2.0 technological tools used in order to offer e-migration collaborative services hosted in its Web2.0 based-platform. The IMP2.0 user requirement analysis revealed the need for various new e-migration services.

The IMP2.0 serves as an innovative migration system able to host additional emigration services for legal immigrants (e.g. training/ consulting, employment opportunities for legal immigrants, on line applications for labor migration documents, recognition of qualifications, certifications) and stakeholders (e.g. matching employment supply-demand, labor migration monitoring, online processing of migration related documents, one-stop entrance on migration information ) serving their needs and expanding the e-society concept to all its participants.

Acknowledgments. The authors are grateful to the E.C. ICT PSP Programme for funding the ImmigrationPolicy2.0 (IMP2.0) project and all the partners for their valuable contribution. Especial thanks to Professor Wolfgang Bosswick and Verena Krobisch from EFMS for their substantial input in the societal analysis.

\section{References}

1. European Project Immigration Policy 2.0, http : / www . immigrationpolicy2 . eu

2. Bosswick, W., Krobisch, V., Ntouskas, T., Pentafronimos, G., Polemi, N., et al.: D1.1 End User Requirements. European project deliverable, Immigration Policy 2.0 (2011), http: / / www. immigrationpolicy2 . eu / ?q=node/22

3. Pentafronimos, G., Ntouskas, T., Polemi, N., Rodríguez, N., Bosswick, W., et al.: D2.1 User and Service Classification. European project deliverable, Immigration Policy 2.0 (2011), http: / / www . immigrationpolicy2 . eu / ?q=node/22

4. Rodríguez, N., Ntouskas, T., Pentafronimos, G., Polemi, N., Krobisch, V., et al.: D1.2 State-of-the-art and advances in European migration policies. European project deliverable, Immigration Policy 2.0 (2010),

http: / / www. immigrationpolicy2 . eu / ?q=node / 22

5. First Immigration Policy 2.0 Workshop, http: / / www . immigrationpolicy2 . eu / ?q=node/21

6. Pentafronimos, G., Karantjias, A., Polemi, N.: ODYSSEUS: An Advanced, Collaborative and Trusted Framework for the Provision of Migration Services. In: Fifth International Conference on the Internet and Web Applications and Services (ICIW), pp. 531-537. IEEE Computer Society, Barcelona (2010) 
7. Pentafronimos, G., Karantjias, A., Polemi, N.: OPSIS: An Open, Preventive and Scalable Migration Information System. In: Third International Conference on e-Democracy (eDemocracy), pp. 341-350. Springer Lecture Notes, Athens (2009)

8. Karantjias, A., Polemi, N., Pentafronimos, G.: Participatory Immigration Policy Making and Harmonization Services based on Collaborative Web 2.0 Technologies. In: Ahson, S., Ilyas, M. (eds.) Service Delivery Platforms: Developing Converged Multimedia Services HandBook. CRC Press, Taylor \& Francis Group Publishing (March 2011)

9. OpenSSO, http: //java.net/projects/opensso

10. Kate, M.-A., Niessen, J.: Guide to Locating Migration Policies in the European Commission. EPIM and MPG, ed. (2008),

http: / /www. epim.info/docs / documents/137. GuidetoLocatingImmig rationPoliciesintheECII_31.10.08.pdf

11. Collet, E.: The European Union's Stockholm Program: Less Ambition on Immigration and Asylum, But More Detailed Plans. Migration Policy Institute, Migration Information Source (2010),

http: //www.migrationinformation.org/Feature/display. cfm? ID =768

12. Fleischmann, F., Dronkers, J.: The effects of social and labour-market policies of EUcountries on the socio-economic integration of first and second generation immigrants from different countries of origin. In: EUI Working Paper, RCSAS 2007/19, European University Institiute, Florence, Robert Schuman Centre for Advanced Studies (2007)

13. Council Regulation EC 109/2003: Concerning the status of third-country nationals who are long-term residents. Official Journal of the European Union L 16, 44-53 (January 23, 2004)

14. Council Directive EC 86/2003: On the right to family reunification. Official Journal of the European Union L 251, 12-18 (October 03, 2003) 